\title{
Development of Raloxifene Hydrochloride Loaded mPEG-PLA Nanoparticles for Oral Delivery
}

\author{
Shabari Girinath Kala ${ }^{1, *}$, Santhivardhan Chinni ${ }^{2}$ \\ ${ }^{1}$ Research Scholar, Department of Pharmaceutical Sciences, Jawaharlal Nehru Technological University, Ananthapuramu, Andhra \\ Pradesh, INDIA. \\ ${ }^{2}$ Associate Professor, Raghavendra Institute of Pharmaceutical Education and Research (RIPER), Anantapuramu, Andhra Pradesh, \\ INDIA.
}

\begin{abstract}
Objectives: Raloxifene hydrochloride is used in the treatment of breast cancer which suffers from poor bioavailability problem i.e., only $2 \%$ due to excessive first pass metabolism. Development of a delivery system to overcome its bioavailability problem can be done by using MPEG-PLA polymeric nanoparticles which has many scientific applications. Methods: mPEG-PLA polymer has been prepared and evaluated using NMR, FTIR and GPC. Nanoparticles were prepared using emulsion-diffusion-evaporation technique and drug release patterns were evaluated. Pharmacokinetic study was done using Sprague dawley rats to increase the drugs bioavailability. Analytical method was developed with an LOO $0.5 \mu \mathrm{g} / \mathrm{ml}$ and LOD $0.167 \mu \mathrm{g} / \mathrm{ml}$. Results: Nanoparticles were formulated using synthesized mPEG-PLA polymer has a particle size range of 165-180 $\mathrm{nm}$. In vitro release study showed, about $72 \%$ of drug was released from nanoparticles over the given time duration and showed sustained release for 20 days following Higuchi kinetics. Pharmacokinetic study showed that drug loaded nanoparticles were having approximately 4.87 times more bioavailability than the free drug. Conclusion: Raloxifene hydrochloride loaded nanoparticles prepared with the synthesized mPEGPLA polymer which can release the drug slowly and were suitable for oral delivery. From pharmacokinetic study, it was observed that raloxifene hydrochloride loaded nanoparticles were found to show an increase of relative oral bioavailability to that of raloxifene hydrochloride suspension.
\end{abstract}

Key words: First pass metabolism, mPEG-PLA, Nanoparticles, Emulsion diffusion evaporation method, Bioavailability and Higuchi diffusion.

\section{INTRODUCTION}

Breast cancer is the most frequent cancer in women worldwide and estrogen receptor positive plays a major role in breast cancer. Harmonal drugs used in postmenopausal women which have the ability to treat the breast cancer effectively are tamoxifen, raloxifene, ormeloxifen, but the drug tamoxifen has many severe adverse effects so a Study of Tamoxifen And Raloxifene (STAR) trial ${ }^{1}$ had been conducted in 2006 by the National Cancer Institute and announced that raloxifene was as effective as tamoxifene with no severe side effects. Raloxifene hydrochloride was also prescribed for treating osteoporosis. ${ }^{2}$ Marketed tablets of raloxifene hydrochloride suffer from poor bioavailability which may be due to poor solubility of the drug. In order to solve this problem, studies were done to increase the solubility and dissolution rate using microwave energy to prepare solid dispersion. ${ }^{3}$ Nanotechnology which is one of the frontier sciences, had overcome the barriers of conventional tablets by delivering the drugs as colloidal nanocarriers. ${ }^{4}$ Out of different colloidal carriers, polymeric nanoparticles seems to offer many advantages like stability, processability, ability for surface modification etc. and this drug delivery is the best approach available to the formulation
Submission Date: 16-06-2020; Revision Date: 30-07-2020; Accepted Date: 14-09-2020

DOI: 10.5530/ijper.55.1s.44 Correspondence: Mr. Shabari Girinath Kala Research Scholar, Jawaharlal Nehru Technological University, Anantapuramu-515002, Andhra Pradesh, INDIA. Phone no: +919490120635 Email id: shabari.niper@ gmail.com

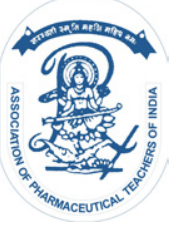

www.ijper.org 


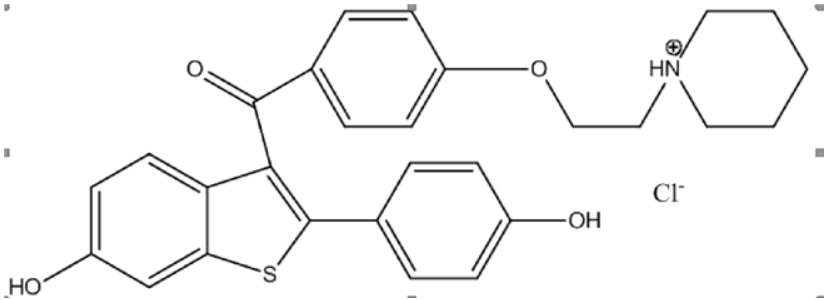

Figure 1: Chemical structure of raloxifene hydrochloride.

scientist for targeting of anticancer agents. There is a requirement to formulate a drug delivery system to distribute drug molecules like raloxifene hydrochloride wherein disease, drug, destination and delivery are considered together to solve a particular problem. ${ }^{5}$

Raloxifene hydrochloride (Figure 1) is prescribed for treating osteoporosis ${ }^{2}$ and recently studies were done with the drug loaded implants which showed initial bursts followed with localized long action for about 2 months. ${ }^{6}$ In addition to this, the US FDA announced approval of raloxifene hydrochloride for the treatment of post-menopausal women with invasive breast cancer on september 14, 2007.

Nanoparticulate formulations explored for raloxifene hydrochloride include polyester based nanoparticles for intravenous delivery ${ }^{7}$ and Micellar nanoparticles for transdermal delivery. ${ }^{8}$ The available dosage form of the drug in the market has very less bioavailability of $2 \%$. Thus, the formulation of successful novel delivery system is crucial for a better clinical application. Nanoparticles of perishable polymers could offer another resolution for oral delivery of malignant neoplasm medication across the epithelial duct barrier because of their very tiny size and their ability to flee from the detection by P450/ P-GP.

The polymeric nanoparticles like PLA, PLGA and PCL are biodegradable and biocompatible hence they are routinely employed in drug delivery as they can readily encapsulate hydrophobic drugs. The major disadvantages are rapid hydrolysis and the hydrophobic surface which attract plasma proteins were recognized through mononuclear phagocytic system (MPS) which ultimately results in faster elimination. ${ }^{10,11}$

The hydrophobic surface of the above mentioned nanoparticles is mainly responsible for their macrophage uptake. In order to prevent the uptake of nanoparticles factors like particle size and surface property should be considered which play a vital role in enhancing the protein adsorption. ${ }^{12}$ Particles of size less than $250 \mathrm{~nm}$ (by subjecting to homogenization) and a hydrophilic surface (by doing PEGylation) is necessary to prevent

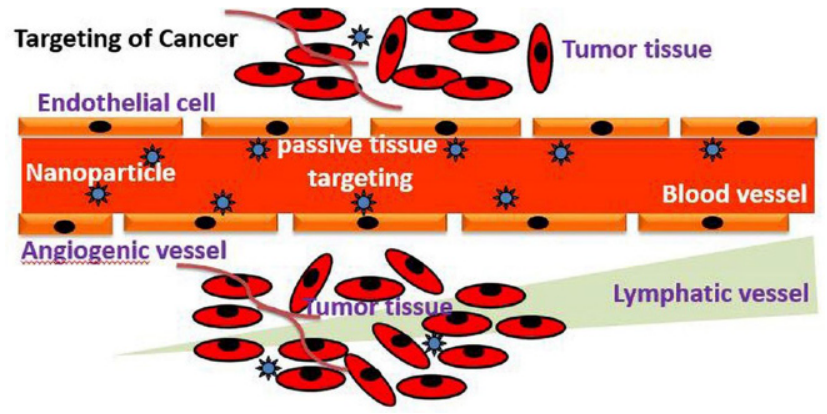

Figure 2: Extravasation of long circulating nanoparticles in tumor interstitium by passive and active targeting.

opsonisation reactions and subsequent clearance by macrophage ${ }^{13}$ so as to escape from MPS were called as stealth nanoparticles. This complete process helps in increasing circulation time of nanoparticles in central compartment, hence enhanced drug activity through increased drug deposition in tumors (Figure 2). ${ }^{14}$ Hydrophilic polymers such as polyethylene oxide (PEO), chitosan, polyvinyl alcohol (PVA), polyethylene glycol (PEG) etc. are used to impart surface hydrophilicity to nanoparticles. Among these polymers, PEG is widely used to prevent rapid clearance because the hydrophilic nature of nanoparticles protects them from MPS uptake and at the same time it also affects their uptake by cancer cells. It is FDA approved for use in pharmaceuticals, shows little toxicity, lacks immunogenicity and eliminated from the body easily. ${ }^{15}$ Hydrophobicity and flexibility of PEGylated nanoparticles prevents the protein adsorption, which in turn reduces the rate of uptake of nanoparticles by the MPS. ${ }^{16}$ Cytotoxicity of nanoparticles to cancer cells is dependent on particle size, drug loading and hydrophilic-hydrophobic balance of the nanoparticles surface. So, hydrophobic to hydrophilic properties on the surface is important for optimum efficiency of nanoparticulate system. ${ }^{17}$

Based on the above information it can be concluded that a hydrophobic polymer (PLA, PLGA, PCL) if conjugated along with the hydrophilic polymer (PEG), the drug loaded nanoparticles will have many advantages. ${ }^{18}$

Drug administration through oral route is the most convenient, safe and least expensive, ${ }^{19}$ however according to the biopharmaceutical point of view it is not always the better route because after oral administration, the drug has to pass through gastro intestinal tract (GIT) and liver, during this process it undergoes first pass metabolism before it reaches the target site via the systemic circulation. ${ }^{20}$ 


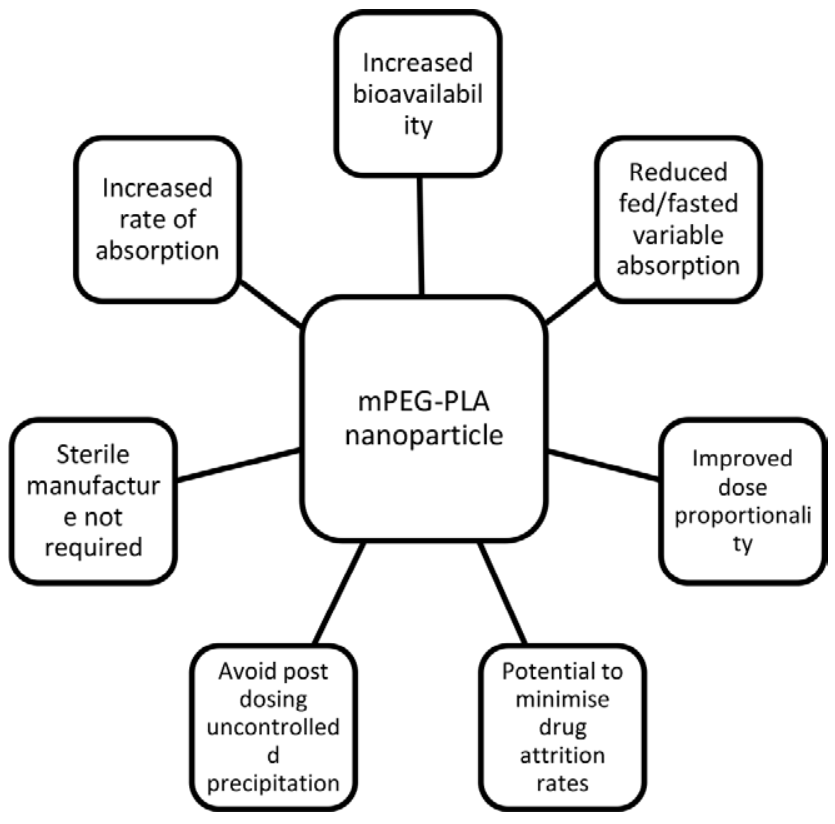

Figure 3: Possible advantages of oral mPEG-PLA nanoparticles.

The drug raloxifene hydrochloride is available in the market as EVISTA ${ }^{\circledR} 60 \mathrm{mg}$ for oral route, which has very less bioavailability of $2 \%$ due to extensive glucoronide conjugation and poor solubility. ${ }^{3}$ In order to increase the bioavailability and to decrease the toxicity of the drug, till date the drug formulation was developed in nanoparticle system within the kind of polyester based nanoparticles and micellar nanoparticles as described previously. These approaches were designed to deliver needed quantity of drug at desired site lowering adverse effects on body organs by intravenous route and transdermal route of administration respectively and not for oral route of administration. On observing the previously mentioned delivery systems, mPEG-PLA polymeric nanoparticles seems to be the more effective delivery system as it has the following advantages ${ }^{21}$ (Figure 3 ).

\section{MATERIALS AND METHODS}

\section{Materials}

Raloxifene hydrochloride acquired from $\mathrm{M} / \mathrm{s}$. IndSwift Labs, Manimajra, Punjab, India as a gratis sample. Haloperidol was obtained from Sigma Aldrich, India. dl-Lactide from Sigma, USA. Polyethylene glycol (MW $5000 \mathrm{Da}$ ) and stannous 2-ethylhexanoate from Sigma Aldrich (Germany). Polystyrene Standards were purchased form Polymer Standard Services, USA. Pepsin (hog stomach), Pancreatin (Pig pancreas) was procured from Loba chemie, India and MCF-7 cell lines from Sigma Aldrich, India.

\section{Methods}

\section{HPLC analytical method development and validation}

Shimadzu HPLC system coupled to UV-Visible detector having Class VP software using Sunfire ${ }^{\mathrm{TM}}$ column, $25 \mathrm{~cm} \times 4.6 \mathrm{~mm}$, (Ireland) maintained at $30^{\circ} \mathrm{C}$ in isocratic mode was used for analytical method development. Mobile phase selected for the estimation was phosphate buffer $(10 \mathrm{mM})$ : acetonitrile viz method-1 with 64:36 at $\mathrm{pH} 4$, method-2 with 60:40 at $\mathrm{pH} \mathrm{5,}$ method-3 with 60:40 at $\mathrm{pH} 4$ and method- 4 with 64:36 at $\mathrm{pH} 5$ respectively (different ratios) ${ }^{22}$ filtered through $0.45 \mu \mathrm{m}$ filter. Standard solutions of concentration range 2 to $20 \mu \mathrm{g} / \mathrm{ml}$ were prepared for calibration curves $^{23}$ and injected the sample of $50 \mu$ at a flow rate of $1 \mathrm{ml} / \mathrm{min}$ and analyzed at wavelength $288 \mathrm{~nm}$ for range, accuracy, linearity, specificity and precision.

\section{Bioanalytical method development and validation}

Determination of drug in plasma was done using HPLC with Sunfire $C_{18}(5 \mu \mathrm{m}, 250 \mathrm{~mm} \times 4.6 \mathrm{~mm})$ column consisting of acetonitrile and phosphate buffer $(10 \mathrm{mM})(60: 40)$ as mobile phase with flow rate $1 \mathrm{ml} /$ min in isocratic mode. Detection was carried out at $288 \mathrm{~nm}$ for raloxifene hydrochloride and at $254 \mathrm{~nm}$ for haloperidol (internal standard). The calibration curve has been prepared within 50 to $1000 \mathrm{ng} / \mathrm{ml}$ range. The parameters such as accuracy, precision, recovery, lower limit of quantification (LLOQ), stability etc. were validated for the developed method.

\section{Sample preparation}

Stock solution of raloxifene hydrochloride $(50 \mu \mathrm{g} / \mathrm{ml})$ was prepared and calibration curve drawn within 50 to $1000 \mathrm{ng} / \mathrm{ml}$ range, $100 \mu \mathrm{l}$ of standard raloxifene hydrochloride solution $(10 \mu \mathrm{g} / \mathrm{ml})$ and $100 \mu \mathrm{l}$ of haloperidol $(10 \mu \mathrm{g} / \mathrm{ml})$ were added to $100 \mu \mathrm{l}$ of plasma. The above mixture was vortexed for $5 \mathrm{~min}$ by adding 1 $\mathrm{ml}$ methanol and centrifuged at $6000 \mathrm{~g}$ for $15 \mathrm{~min}$. The supernatant was collected, allowed to dry using centrivac dryer and stored at $-20^{\circ} \mathrm{C}$ until analysis. The sample was reconstituted in $100 \mu \mathrm{l}$ of methanol and centrifuged at $10000 \mathrm{~g}$ for $10 \mathrm{~min}$ and $80 \mu \mathrm{l}$ of supernatant injected into HPLC for analysis using validated bioanalytical method.

\section{Synthesis and Characterization of mPEG-PLA copolymers}

mPEG-PLA copolymer prepared by ring opening polymerization (ROP) of recrystallized D,L-lactide monomers with dried methoxy polyethylene glycol (mPEG 5000 Daltons with 10\% w/w feed ratio) in 


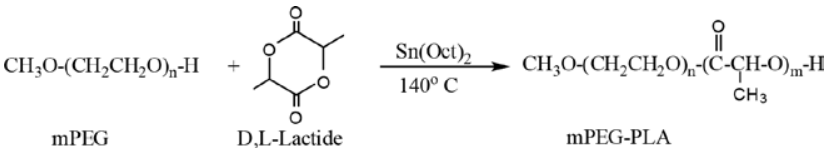

Figure 4: Synthesis of mPEG-PLA polymer.

appropriate amounts (Figure 4$)^{24}$ placed in round bottom flask with temperature maintained at $120^{\circ} \mathrm{C}$ for $2 \mathrm{~h}$. Stannous octanoate $(0.2 \% \mathrm{w} / \mathrm{w})$ dissolved in toluene added as a catalyst under nitrogen purging to the reaction mixture and vacuum was applied. The temperature of synthesis flask raised to $140^{\circ} \mathrm{C}$ and copolymerization was allowed for $12 \mathrm{~h}$ after which the reaction was stopped by cooling the round bottom flask and the raw polymer thus prepared was refined by dissolving in dichloromethane, followed by precipitation in an excess of cold isopropyl alcohol. The purification was done thrice and then dried at $30^{\circ} \mathrm{C}$ for $48 \mathrm{~h}$ in vacuum oven. The synthesized copolymer was characterized by GPC, ${ }^{1}$ HNMR spectroscopy and FTIR spectroscopy.

\section{Gel Permeation Chromatography (GPC)}

Weight average molecular weight $(\mathrm{Mw})$, number average molecular weight $(\mathrm{Mn})$ and polydispersity index $(\mathrm{Mw} /$ $\mathrm{Mn}$ ) of the copolymers were calculated using GPC coupled to refractive index detector using class VP software with styragel HR3 column at $30^{\circ} \mathrm{C}$. Mobile phase chloroform was filtered using $0.45 \mu \mathrm{m}$ filter paper. Standards and samples $(1 \mathrm{mg} / 2 \mathrm{ml})$ were prepared by mixing polymer in HPLC grade chloroform and filtered by $0.45 \mu \mathrm{m}$ filter paper. Sample was injected by hamilton syringe in to the GPC at a flow rate $1 \mathrm{ml} / \mathrm{min}$ and calibration curves were generated using the polystyrene standards of molecular weights 3,460, 5,610, 12,500, 27,500, 51,500 and 1,25,000 Daltons.

\section{Nuclear Magnetic Resonance spectroscopy ('H NMR)}

The synthesized polymer was analyzed by ${ }^{1} \mathrm{H}$ NMR at $400 \mathrm{MHz}$ by dissolving it in deuterated chloroform and the spectrum was recorded from $0-10 \mathrm{ppm}$ chemical shift $(\delta)$.

\section{Fourier Transform Infrared Spectroscopy (FTIR)}

The spectra for the polymer was recorded by mixing the polymer sample with $\mathrm{KBr}$ to form a pellet which was then analyzed in the IR region $\left(4000-400 \mathrm{~cm}^{-1}\right)$.

\section{Solubility studies}

For a successful development of a nanoparticulate formulation, the identification of the organic solvent is incredibly crucial. The toxicity of the solvent is also taken into account during solvent selection procedure because some residual solvent is may be present in the final formulation. ${ }^{25}$ The solvent selection depends upon the method of the preparation of the nanoparticles. Generally water-immiscible solvents like methylene chloride, ethyl acetate or chloroform is used for single emulsion and double emulsion methods and a partially water-soluble solvent like benzyl alcohol, acetone, DMSO is used in the emulsion/diffusion and solvent displacement techniques.

For solubility study, excess of drug is added in $1 \mathrm{ml}$ of methanol, ethyl acetate, dichloromethane, ethanol, water, acetonitrile, acetone, chloroform, $1 \%$ Tween $^{\circledR} 80$ and $2 \%$ Tween $^{\circledR} 80$ etc. and was equilibrated for $24 \mathrm{hr}$ in reciprocating shaker at $30^{\circ} \mathrm{C}$ and $100 \mathrm{rpm}$ to achieve the equilibrium solubility. The sample was centrifuged at $10,000 \mathrm{rpm}$ for $10 \mathrm{~min}$ and supernatant collected. The volume was noted and solvent was vaporised by nitrogen purging. The precipitant was dissolved in methanol and drug content was determined using developed method.

\section{Preparation of raloxifene hydrochloride loaded nanoparticles}

Polymeric nanoparticles were formulated using emulsion diffusion evaporation method. Synthesized polymer and drug (5-15\%) were solubilized in $2.5 \mathrm{ml}$ of organic solvent and mixed to $5 \mathrm{ml}$ of aqueous phase with surfactant of concentration $(1-2 \% \mathrm{w} / \mathrm{v})$ under stirring $(1000 \mathrm{rpm})$ which was then homogenized at suitable speed $(20,000 \mathrm{rpm})$ to form fine emulsion and then allowed for organic phase evaporation (4-5 h) after injecting this emulsion drop wise in to PVA $(0.5 \%)$. The formed nanoparticles were centrifuged $(15,000 \mathrm{~g})$ to separate the un-entrapped drug and supernatant containing nanoparticles was separated and to be centrifuged again. The nanoparticles settled after centrifugation were washed twice with $15 \mathrm{ml}$ water.

\section{Optimization of raloxifene hydrochloride loaded nanoparticles}

Suitable organic phase was screened using ethyl acetate, acetone, dichloromethane, methanol and dimethyl sulfoxide in sufficient ratios to dissolve drug and polymer completely and nanoparticles were prepared keeping the other parameters constant. Nanoparticles were optimized by preparing with $1 \%, 1.5 \%$ and $2 \%$ w/v PVA as a stabilizer ${ }^{26}$ keeping the other parameters constant to achieve the desired particle size with good entrapment efficiency and drug loading. Theoretical drug loading effect on entrapment efficiency and particle size were optimized by varying drug loading 
from $5-15 \% \mathrm{w} / \mathrm{w}$ of polymer keeping other process parameters like homogenization speed $(20,000 \mathrm{rpm}$ for $5 \mathrm{~min}$.) and PVA (concentration) constant.

\section{Characterization of the raloxifene hydrochloride loaded nanoparticles}

Zeta potential, size of the particle and size distribution (polydispersity index) were evaluated in triplicate with zeta sizer in double distilled water. Encapsulation efficiency and drug loading were determined by monitoring free drug at its $\lambda_{\max }(288 \mathrm{~nm})$ or by dissolving the nanoparticles and then estimating the drug entrapped in the nanoparticles using the validated method with below equations (1) and (2).

$$
\text { Drug loading }(\% \mathrm{w} / \mathrm{w})=\frac{\begin{array}{l}
\text { Amount of drug } \\
\text { encapsulated }
\end{array}}{\begin{array}{l}
\text { Total weight of } \\
\text { nanoparticles }
\end{array}} \times 100
$$$$
\text { Encapsulation efficiency }(\%)=\frac{\begin{array}{l}
\text { Amount of drug } \\
\text { encapsulated }
\end{array}}{\begin{array}{l}
\text { Total amount of } \\
\text { drug taken }
\end{array}} \times 100
$$

\section{Freeze drying of the Nanoformulation}

Lyoprotectants showed the protective effect by preventing the collapse and aggregation of particles due to stress condition under freezing and drying stage. ${ }^{27,28}$ Lyoprotectants were added to the formulation for circumventing freezing and desiccation stresses. ${ }^{29}$ Drug loaded formulation was lyophilized using VirTis freeze dryer (Wizard 2.0) by suspending different lyoprotective agents such as trehalose, sucrose, dextrose, sorbitol and mannitol in glass vials which were screened for their use at $5 \% \mathrm{w} / \mathrm{v}$. The lyophilization cycle as shown (Table 1) was used. The lyophilized samples were reconstituted in demineralized water and size of the particle obtained was compared with its initial mean particle size.

\section{Characterization of the freeze dried nanoparticles Scanning Electron Microscopy (SEM)}

Nanoparticles were dried on a glass cover slide, allowed to dry at room temperature and kept on a metal stab with double sided carbon tape adhesive and then sputtered a very thin layer of conductive metal (carbon or gold) in an ion sputter. (E1010, Hitachi, Japan) under vacuum of $10 \mathrm{~Pa}$ for $30 \mathrm{sec}$. After coating the sample was transferred to the SEM (S3400N, Hitachi, Japan) instrument and observed at $9.5 \mathrm{~mm}$ working distance
Table 1: Lyophilization cycle for freeze drying of raloxifene hydrochloride loaded nanoparticles.

\begin{tabular}{|c|c|c|c|c|c|}
\hline \multicolumn{3}{|c|}{ Freezing } & \multicolumn{3}{c|}{ Primary drying (vacuum) } \\
\hline Step & $\begin{array}{c}\text { Temp. } \\
\left({ }^{\circ} \mathbf{C}\right)\end{array}$ & $\begin{array}{c}\text { Time } \\
(\mathbf{m i n} .)\end{array}$ & Step & $\begin{array}{c}\text { Temp. } \\
\left({ }^{\circ} \mathbf{C}\right)\end{array}$ & $\begin{array}{c}\text { Time } \\
(\text { min.) }\end{array}$ \\
\hline 1 & 25 & 10 & 1 & -60 & 180 \\
\hline 2 & 15 & 30 & 2 & -45 & 360 \\
\hline 3 & 10 & 30 & 3 & -30 & 360 \\
\hline 4 & -5 & 60 & 4 & -20 & 420 \\
\hline 5 & -15 & 60 & 5 & -10 & 360 \\
\hline 6 & -25 & 60 & 6 & -5 & 180 \\
\hline 7 & -45 & 30 & 7 & 10 & 120 \\
\hline 8 & -60 & 120 & 8 & 20 & 120 \\
\hline & \multicolumn{7}{|c|}{ Secondary drying } \\
\hline 1 & 25 & 300 & 9 & 15 & 30 \\
\hline
\end{tabular}

and the power of X-rays was kept $15.0 \mathrm{kV}$. Image was captured by random scanning of the stub at various levels of magnification.

\section{X-Ray Diffraction (XRD)}

The crystalline property of the drug before and after nanoparticles formation was determined by subjecting 4-5 $\mathrm{mg}$ of the polymer, drug and drug loaded NPs at $2 \theta$ diffraction angle set from $3^{\circ}$ to $40^{\circ}$ with $3^{\circ} \mathrm{C} / \mathrm{min}$ speed. $\mathrm{X}$-ray radiation from the copper source was used at 40 $\mathrm{Kv}$ and $40 \mathrm{~mA}$.

\section{In-vitro release study}

Phosphate buffer $100 \mathrm{mM}$ containing Tween ${ }^{\circledR} 80$ of $0.5 \% \mathrm{w} / \mathrm{v}$ was used in order to solubilize the drug. Dialysis membrane (MWCO 10,000) was tied on one end and nanoparticles (equivalent to $3 \mathrm{mg}$ of drug) suspended in $5 \mathrm{ml}$ release medium, were kept in dialysis bag. The bags were again tied firmly from other end and kept in $30 \mathrm{ml}$ vials containing $20 \mathrm{ml}$ release medium in a shaker water bath kept at $37^{\circ} \mathrm{C}$ and $100 \mathrm{rpm} .1 \mathrm{ml}$ of release medium was withdrawn and equal volume of fresh medium replaced at specific time intervals. The withdrawn samples were kept in refrigerator until analysis. The analysis was done by using developed HPLC analytical method and release data was evaluated by model dependent analysis using the mathematical equations with best goodness-of-fit.

\section{In vitro cytotoxicity of nanoparticles}

Breast cancer cell lines (MCF-7) were seeded with a cell density of $1 \times 10^{5}$ in a 96-well plate along with the culture media and incubated for $24 \mathrm{~h}$ for cell attachment. Culture medium was removed after $24 \mathrm{~h}$ and fresh medium with nanoparticles (equivalent to 0.1, $1,10,50,100,500$ and $1000 \mu \mathrm{M}$ ) were added. Similarly 
in another set of wells, drug solution was also tested. The wells without nanoparticles or drug solution were kept as control and incubated for $48 \mathrm{~h}$ and $72 \mathrm{~h}$. The culture medium containing nanoparticles were removed at the end of each time point and incubated for $4 \mathrm{~h}$ with MTT solution $(50 \mu \mathrm{g} / \mathrm{ml})$. At the end of $4 \mathrm{~h}$, culture medium was withdrawn and formazan crystals formed were dissolved using DMSO. The absorbance was measured using ELISA plate reader at $\lambda_{\text {max }} 570 \mathrm{~nm}$ and $630 \mathrm{~nm}$. The cell viability was enumerated with equation (3) along with drug and nanoparticle efficacy which were measured as $\mathrm{IC}_{50}$ values.

$$
\text { Cell Viability }(\%)=\frac{\text { Absorbance sample }}{\text { Absorbance control }} \times 100
$$

\section{Stability studies of nanoparticles Stability studies in GI fluids}

The lyophilized nanoparticles were tested for their stability in Simulated Gastric Fluid (SGF) and Simulated Intestinal Fluid (SIF) which was prepared as per United States Pharmacopoeia. Simulated fluids of 10 $\mathrm{ml}$ were mixed with $1 \mathrm{ml}$ of reconstituted lyophilized nanoparticles and incubated at $37^{\circ} \mathrm{C}$ for $2 \mathrm{hr}$ (SGF) and $6 \mathrm{hr}$ (SIF) with $100 \mathrm{rpm}$ in shaker bath based on the residence time of the formulation in stomach and intestine. The nanoparticles characteristics were then evaluated for various parameters.

\section{Accelerated stability studies}

The lyophilized nanoparticles in $5 \mathrm{ml}$ sealed glass vials were kept in stability chamber at $(40 \pm 2)^{\circ} \mathrm{C} /(75 \% \pm 5 \%)$ $\mathrm{RH}$ for six months and evaluated for appearance, PDI, particle size, encapsulation efficiency, reconstitution time and ease of reconstitution.

\section{Pharmacokinetic study}

Male Sprague dawley rats weighing 150-250 g $(n=4)$ were kept under fasting condition overnight prior to the study. Drug suspension in sodium CMC $(2.5 \% \mathrm{w} / \mathrm{v})$ with a dose of $20 \mathrm{mg} / \mathrm{kg}$ and drug loaded nanoparticles with dose of $20 \mathrm{mg} / \mathrm{kg}$ of body weight were orally administered. Blood samples $(0.5 \mathrm{ml})$ were retrieved through the retro-orbital plexus under mild ether anesthesia into the heparinized micro-centrifuge tubes (containing $20 \mu \mathrm{l}$ of $1000 \mathrm{IU}$ heparin/ml of blood) at different time intervals. After each sampling, normal saline of $1 \mathrm{ml}$ was given to avoid variation in the central compartment volume. Centrifugation was done to separate the plasma the blood samples at $10000 \mathrm{~g}$ for $10 \mathrm{~min}$ at $15^{\circ} \mathrm{C} .100 \mu \mathrm{l}$ of haloperidol $(10 \mu \mathrm{g} / \mathrm{ml})$ and methanol $(0.5 \mathrm{ml})$ were added to $100 \mu \mathrm{l}$ of plasma and vortexed for 5 min. Centrifugation was done at 10,000 $\mathrm{g}$ for $10 \mathrm{~min}$ and organic layer was separated which contains the drug. The supernatant was vaporised using centrivac dryer and the residue left was subjected to reconstitution in $100 \mu \mathrm{l}$ of methanol and analyzed using the validated bioanalytical method.

\section{RESULTS}

\section{HPLC analytical method development and validation}

The method-1 yielded best results with resolved peak (Figure 5) at $5.2 \mathrm{~min}$. retention time using mobile phases ACN: $\mathrm{KH}_{2} \mathrm{PO}_{4}$ (36:64) at $288 \mathrm{~nm}$ wavelength on reverse phase HPLC column and method-2, method-3, method-4 had retention times $8.0 \mathrm{~min}, 8.1 \mathrm{~min} 10.3 \mathrm{~min}$ respectively. This method had been taken for further validation and the calibration curve was found to be linear $\left(r^{2}=0.998 \pm 0.001\right)$ within in the range of $2-20$ $\mu \mathrm{g} / \mathrm{ml}$ with an LOQ of $0.5 \mu \mathrm{g} / \mathrm{ml}$, LOD of $0.167 \mu \mathrm{g} /$ $\mathrm{ml}$. The inter and intraday accuracy and precision were within an R.S.D. $\leq 2 \%)$ at $(n=3)$ and the extraction efficacy in case of spiked plasma samples were $96.52 \pm$ $1.61,99.11 \pm 1.69,98.66 \pm 1.32$ at concentrations of 4 , 12 and $18 \mu \mathrm{g} / \mathrm{mL}$ respectively.

\section{Bioanalytical method development and validation}

The peaks was observed in HPLC chromatogram (Figure 6) without any interference of plasma with raloxifene hydrochloride ( $\mathrm{R} t=5.2 \mathrm{~min}$ ) as well as that of internal standard ( $\mathrm{R} t=6.35 \mathrm{~min})$. The calibration curve was linear $\left(r^{2}=0.998 \pm 0.0008\right)$ within in the range of $50-1000 \mathrm{ng} / \mathrm{ml}$. The inter and intraday accuracy and precision were within an R.S.D. $\leq 15 \%)$ at $(n=5)$ concentrations of 80,400 and $7000 \mathrm{ng} / \mathrm{mL}$. LLOQ was found to be $50 \mathrm{ng} / \mathrm{ml}$.

\section{Synthesis of mPEG-PLA copolymers}

D,L-lactide monomers and mPEG as reactant with $70 \%$ yield was used as a key starting material. The lower

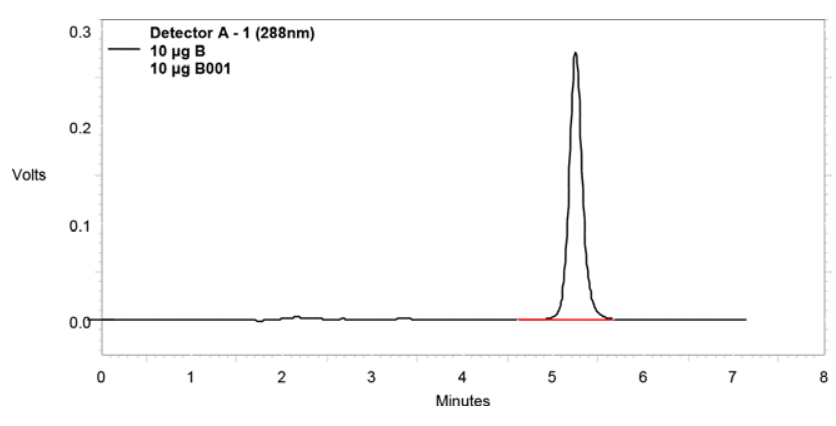

Figure 5: Chromatogram of the raloxifene hydrochloride showing retention time at $5.2 \mathrm{~min}$. 


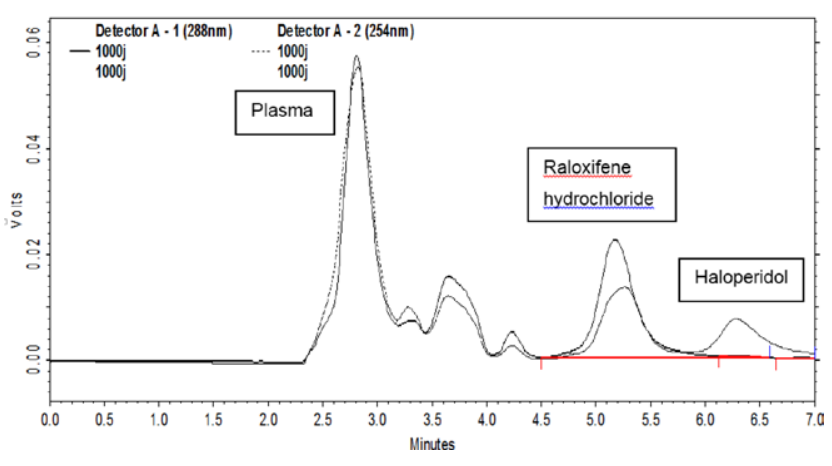

Figure 6: HPLC chromatogram of raloxifene hydrochloride $\left(R_{t}=5.2 \mathrm{~min}\right.$ at $\left.288 \mathrm{~nm}\right)$ and haloperidol (IS) $\left(R_{t}=6.35 \mathrm{~min}\right.$ at $254 \mathrm{~nm})$.

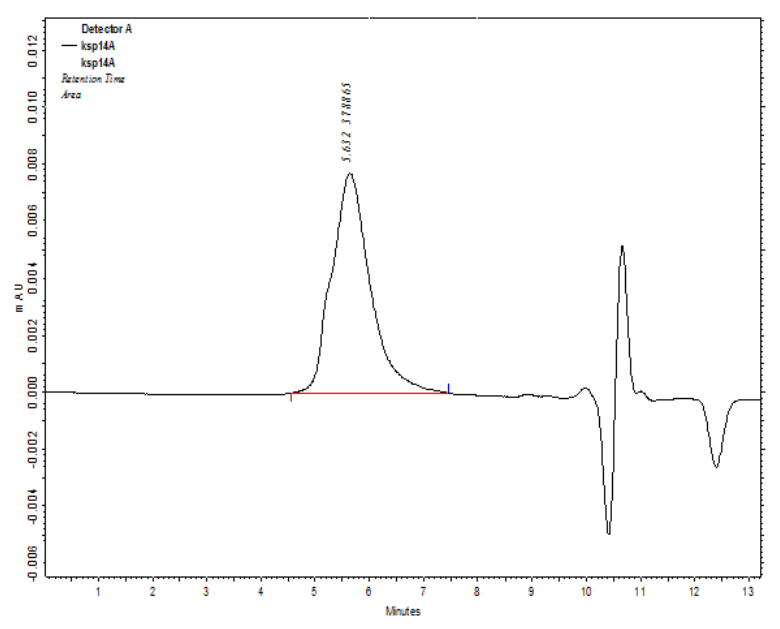

Figure 7: GPC Chromatogram of mPEG-PLA polymer.

yield of polymers could be attributed to partial reaction mPEG and D,L-lactide and formation of low molecular weight polymer chains. Both mPEG and small molecular weight polymer chains are soluble in isopropyl alcohol and hence were removed during purification step. The synthesized polymer was further characterized by GPC, NMR and FTIR.

\section{Characterization of MPEG-PLA copolymers Gel Permeation Chromatography (GPC)}

Single symmetrical unimodal peak in GPC having a narrow molecular weight distribution confirms the purity of the copolymers. (Figure 7) The peak having retention time of $5.6 \mathrm{~min}$ based on molecular weight.

\section{Nuclear Magnetic Resonance spectroscopy $\left({ }^{1} \mathrm{H}\right.$ NMR)}

Spectrum of ${ }^{1} \mathrm{H}$ NMR (Bruker 400 Ultrashied $^{\mathrm{TM}}$ ) (Figure 8) shows the integrals of peaks corresponding to $-\underline{\mathrm{CH}}_{3}$ and $-\mathrm{C} \underline{\mathrm{H}}$ - groups of PLA block and the terminal $-\mathrm{OCH}_{3}$ and $-\mathrm{CH}_{2}$ groups of $\mathrm{mPEG}$ block $^{30}$

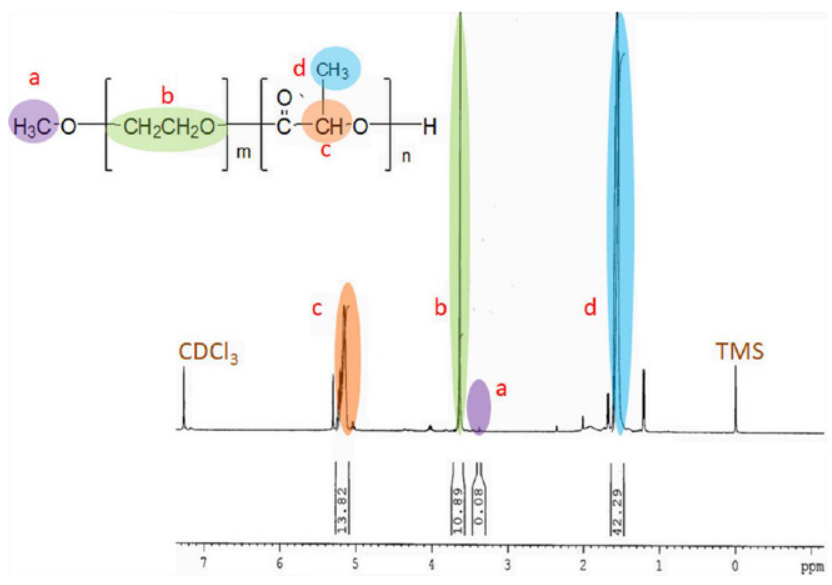

Figure 8: Representative NMR spectra of polymer showing characteristic peaks for different kinds of protons.

Table 2: Characterization of MPEG-PLA Polymer By
NMR.
\begin{tabular}{c|c|c|c|} 
Peak & Proton & Shift (ppm) & $\begin{array}{c}\text { Proton } \\
\text { integral area }\end{array}$ \\
\hline A & $-\mathrm{OC}_{\underline{3}}$ of mPEG & 3.40 & 0.08 \\
\hline B & $-\mathrm{OC}_{\underline{2}} \underline{\mathrm{CH}}_{2}$ of $\mathrm{mPEG}$ & 3.68 & 10.89 \\
\hline C & $-\mathrm{C}_{\mathrm{H}}$ - of Lactide & 5.15 & 13.82 \\
\hline D & $-\underline{\mathrm{H}}_{\underline{3}}$ Lactide & 1.56 & 42.29 \\
\hline
\end{tabular}

\begin{tabular}{|c|c|c|}
\hline \multicolumn{3}{|c|}{ Table 3: Characterization of Feed Ratio of } \\
MPEG-PLA Polymer By NMR. \\
\hline $\begin{array}{c}\text { Polymer } \\
\text { Nomenclature }\end{array}$ & $\begin{array}{c}\text { Theoretical feed ratio } \\
\text { of mPEG : D,L-Lactide }\end{array}$ & $\begin{array}{c}\text { Practical feed } \\
\text { ratio* } \\
\text { of mPEG : D,L- } \\
\text { Lactide }\end{array}$ \\
\hline mPEG-PLA & $10: 90$ & $16: 84$ \\
\hline
\end{tabular}

*Practical feed ratio was calculated by integral area values obtained from NMR

were used to calculate the mPEG content in synthesized copolymers (Table 2, 3). The Weight average molecular weight $(\mathrm{Mw})$, Number average molecular weight $(\mathrm{Mn})$ and Polydispersity index $(\mathrm{Mw} / \mathrm{Mn})$ were calculated based on the proton integral area and were found to be $53.96 \mathrm{kDa}, 37.68 \mathrm{kDa}$ and 1.43 respectively.

\section{Fourier Transform Infrared Spectroscopy (FTIR)}

Synthesized mPEG-PLA copolymer with different functional groups are present in the spectra (Figure 9). Appearance of characteristic ester peak (Table 4) for mPEG-PLA at $1756 \mathrm{~cm}^{-1}$ confirms that the polymer was synthesized.

\section{Solubility studies}

Solubility of raloxifene hydrochloride was studied by using dynamic equilibrium method in various solvents 


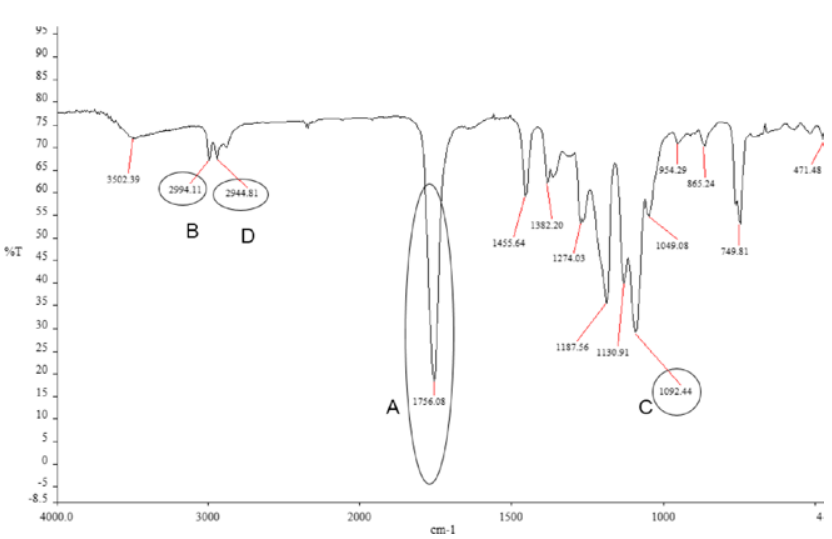

Figure 9: Representative FTIR spectra of polymer showing characteristic peaks for different kinds of functional groups.

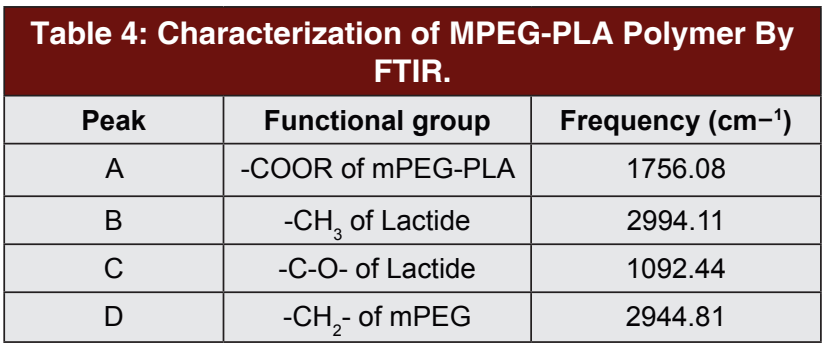

\begin{tabular}{|c|c|}
$\begin{array}{c}\text { Table 5: Solubility of the Raloxifene Hydrochloride in } \\
\text { Different Solvents. }\end{array}$ \\
\hline Solvents & Solubility (mg/ml) \\
\hline $1 \%$ Tween $^{\circledR} 80$ & $0.041 \pm 0.001$ \\
\hline $2 \%$ Tween $^{\circledR} 80$ & $0.057 \pm 0.001$ \\
\hline Acetone & $0.040 \pm 0.0003$ \\
\hline Acetonitrile & $0.042 \pm 0.001$ \\
\hline Chloroform $^{\text {DCM }}$ & $0.273 \pm 0.015$ \\
\hline Ethanol & $0.019 \pm 0.0009$ \\
\hline Ethyl acetate & $0.485 \pm 0.035$ \\
\hline Methanol & $0.04 \pm 0.0001$ \\
\hline Water & $4.504 \pm 0.317$ \\
\hline
\end{tabular}

(Data is expressed as mean $\pm S D, n=3$ )

(Table 5) and the results reveal that the raloxifene hydrochloride was highly soluble in methanol and was selected for the solubilisation of the drug in the plasma.

\section{Preparation of raloxifene hydrochloride loaded nanoparticles}

Emulsion diffusion evaporation method was employed for the formulation of nanoparticles with the synthesized mPEG-PLA polymer at a homogenization speed of 20,000 by varying type of organic phase and PVA concentration which provides maximum entrapment efficiency along with optimum size of the particle and polydispersity.

\section{Optimization of raloxifene hydrochloride loaded Nanoparticles}

\section{Screening of type of organic phase}

Ethyl acetate was selected as common solvent and considered to be the best solvent for preparing the polymeric nanoparticles ${ }^{26}$ because it has low boiling point, less viscosity and partially miscible with water. ${ }^{31}$ The nanoparticles prepared with ethyl acetate had bigger particle size, so cosolvents (methanol, DMSO) were added to dissolve the raloxifene hydrochloride and the polymer completely. The particles formed with acetone and DCM combination were of higher particle size because acetone is completely miscible with water so polymer may not be dissolved completely and also it has high interfacial tension than ethyl acetate. From the results it was confirmed that nanoparticles prepared with ethyl acetate and DMSO had achieved lesser particle size when compared to other organic solvents (Table 6 and Figure 10). As per ICH Q3C guidelines, Class 3 (EA and DMSO) solvents posing a lower risk to health ${ }^{26}$ and are selected for optimizing the next step.

\section{Optimization of surfactant concentration}

Nanoparticles were prepared using ethyl acetate and DMSO solvent and the surfactant effect was studied at three different concentrations of PVA i.e., 1\%, 1.5\% and $2 \% \mathrm{w} / \mathrm{v}$. Particle size of nanoparticles remained closer and was not affected much effect by of PVA concentration. Increase in PVA concentration results in reduced size and PDI. The results showed that on varying PVA concentration there is no much difference between $1.5 \%$ and $2 \% \mathrm{w} / \mathrm{v}$ observed (Table 7 and Figure 10) however at $1 \%$ surfactant concentration, monomers of PVA were available and does not have

\begin{tabular}{|c|c|c|c|}
\hline \multicolumn{4}{|c|}{ Table 6: Optimization of Organic Solvent. } \\
\hline Solvent (Ratio) & $\begin{array}{c}\text { PVA } \\
(\% \text { w/v) }\end{array}$ & Size (nm) & PDI \\
\hline EA+Methanol (4:1) & 0.5 & $448.3 \pm 5.16$ & $0.550 \pm 0.099$ \\
\hline EA+DMSO (24:1) & 0.5 & $353.8 \pm 13.6$ & $0.569 \pm 0.319$ \\
\hline $\begin{array}{c}\text { Acetone+DCM } \\
(1.5: 1)\end{array}$ & 0.5 & $1377 \pm 236.1$ & $0.562 \pm 0.285$ \\
\hline
\end{tabular}

(Data is expressed as mean $\pm S D, n=3$ )

Table 7: Effect of Surfactant Concentration on

Size And Pdi of Raloxifene Hydrochloride Loaded Nanoparticles.

\begin{tabular}{|c|c|c|}
\hline PVA (\% w/v) & Size (nm) & PDI \\
\hline 1 & $170 \pm 1.01$ & $0.10 \pm 0.05$ \\
\hline 1.5 & $162 \pm 1.50$ & $0.07 \pm 0.01$ \\
\hline 2 & $160 \pm 1.50$ & $0.08 \pm 0.01$ \\
\hline
\end{tabular}

(Data is expressed as mean $\pm S D, n=3$ ) 


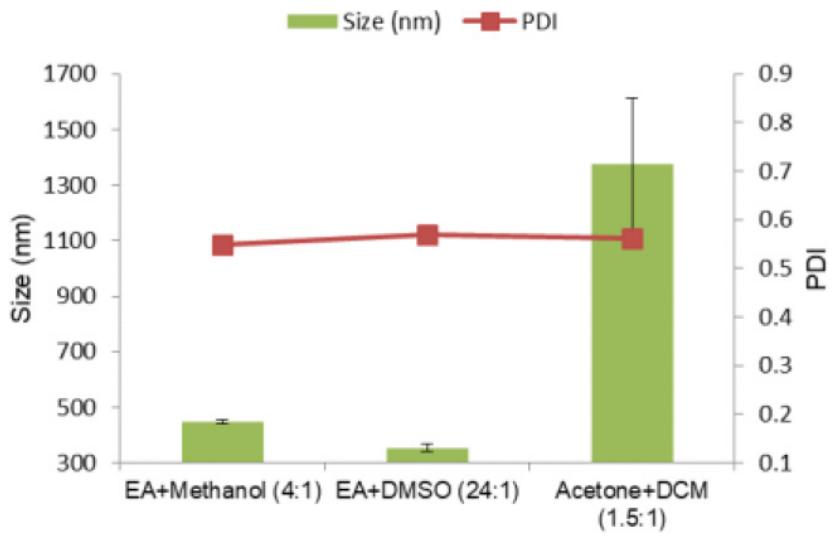

A. Effect of type of solvent on particle size and PDI for nanoparticle preparation

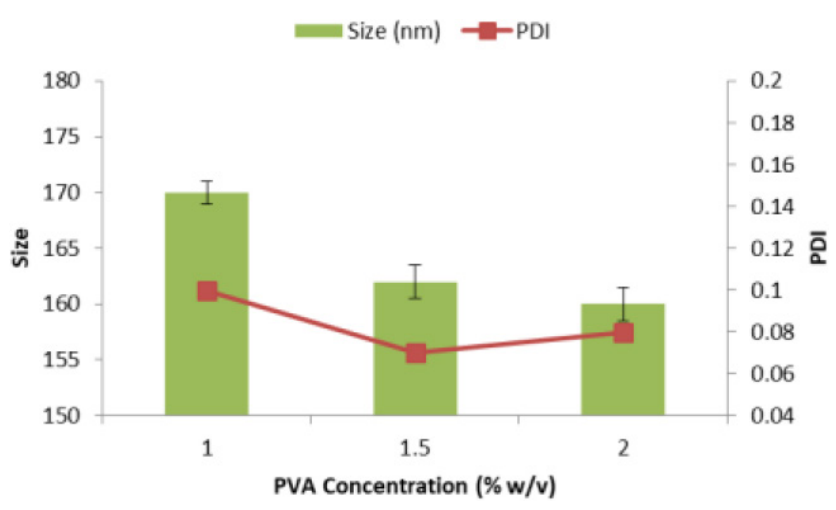

B. Effect of surfactant concentration on particle size and PDI

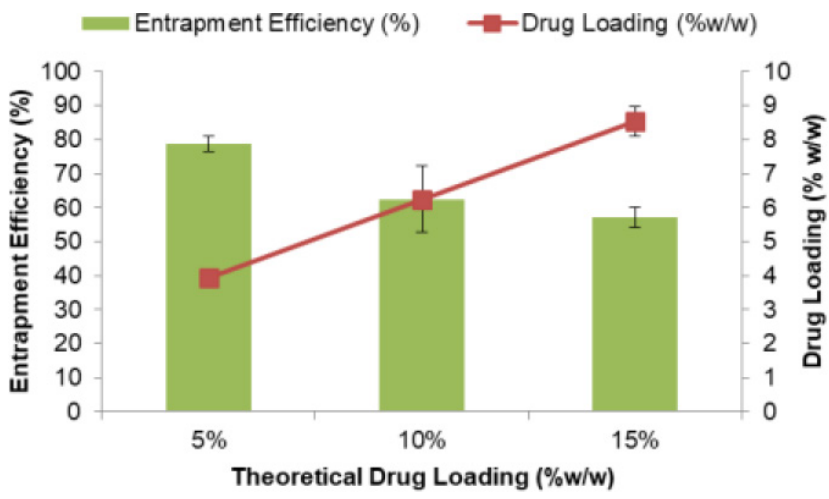

C. Optimization of theoretical drug loading $(\% \mathrm{w} / \mathrm{w})$

Figure 10: Optimization of nanoparticles. the surfactant properties. Hence, the double emulsion formed becomes unstable and shows higher PDI. At a higher concentration the solution contains aggregates which allow droplet stabilization and leads to decrease in size and PDI. Increasing the PVA concentration increases the viscosity and there by results in stable emulsion with smaller and uniform droplet size with low polydispersity. Hence, 1.5\% PVA concentration was selected for optimizing the next step.

\section{Optimization of theoretical drug loading}

Nanoparticles were prepared using ethyl acetate and DMSO solvent with 1.5\% PVA concentration. Theoretical drug loading was optimized for 5\%,10\% and $15 \% \mathrm{w} / \mathrm{w}$ which showed (Table 8 and Figure 10) the drug loading had minimum effect on size and polydispersity. From $5 \%$ to $15 \%$, particles obtained were similar in size and PDI. Entrapment efficiency of the drug decreased with increase in drug loading ${ }^{12,32,33}$ because of saturation of polymer as the drug comes out of the solution during preparation and therefore, loading beyond $15 \%$ was not possible. Hence theoretical loading of $15 \% \mathrm{w} / \mathrm{w}$ provides particles with optimum size, PDI and drug loading.

\section{Freeze drying of Nanoformulation}

The comparison between particle size before and after lyophilization (Figure 11) was shown, particle size and PDI are effectively preserved in presence of sugars due to the formation of a glassy amorphous matrix around the particle, avoiding particle aggregation. ${ }^{34}$ The hydrogen

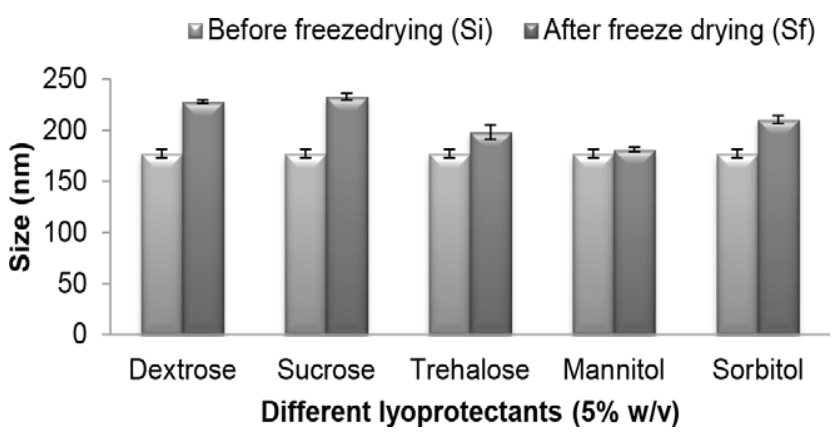

Figure 11: Effect of type of lyoprotectant on size of nanoparticles before and after freeze drying.

\begin{tabular}{|c|c|c|c|c|c|}
\hline \multicolumn{6}{|c|}{ Table 8: Drug Loading And Entrapment Efficiency Values At Different Theoretical Loadings. } \\
\hline $\begin{array}{c}\text { Theoretical } \\
\text { loading (\%w/w) }\end{array}$ & Size (nm) & PDI & $\begin{array}{c}\text { Zeta } \\
\text { potential }\end{array}$ & $\begin{array}{c}\text { Practical loading } \\
(\% \text { w/w) }\end{array}$ & $\begin{array}{c}\text { Encapsulation } \\
\text { Efficiency (\%) }\end{array}$ \\
\hline 5 & $191 \pm 3.75$ & $0.08 \pm 0.02$ & $-0.02 \pm 0.24$ & $3.93 \pm 0.1$ & $78.76 \pm 2.17$ \\
\hline 10 & $193 \pm 2$ & $0.06 \pm 0.02$ & $-0.14 \pm 0.21$ & $6.24 \pm 0.97$ & $62.49 \pm 9.7$ \\
\hline 15 & $194 \pm 2.51$ & $0.09 \pm 0.01$ & $-0.4 \pm 0.03$ & $8.55 \pm 0.43$ & $57.04 \pm 2.91$ \\
\hline
\end{tabular}

(Data is expressed as mean $\pm \mathrm{SD}, n=3$ ) 
bond formation at the end of drying process between sugar and polar groups at surface of nanoparticle also contributes to stabilization. These sugars aid in preserving the native structure of nanoparticle by acting as water substitute. ${ }^{35}$ The particle size was evaluated by re-suspending in $1 \mathrm{ml}$ of water. Sucrose, Dextrose, mannitol, trehalose and sorbitol were screened as lyoprotectants in freeze drying of nanoparticles at $5 \% \mathrm{w} / \mathrm{v}$ concentration and studied for cake formation, particle size and redispersibility. Analysis of lyophilized products was done by observing the final volume, appearance of the intact cake (Figure 12) with same shape and size as that of original frozen mass. The ratio of final particle size $\left(\mathrm{S}_{\mathrm{f}}\right)$ to initial particle size $\left(\mathrm{S}_{\mathrm{i}}\right)$ was found to be $>1$ in case of lyoprotectants such as trehalose, sucrose, dextrose and sorbitol (Table 9) which is due to increase in particle size and Sf/Si ratio was closer to unity after freeze drying with no change in particle size when mannitol was used as a lyoprotectant.

\section{Characterization of the freeze dried nanoparticles}

\section{a) Scanning Electron Microscope (SEM)}

Nanoparticles morphology demonstrates smooth and spherical raloxifene hydrochloride loaded particles after freeze drying (Figure 13) which further confirms the integrity of the particles after freeze drying process.

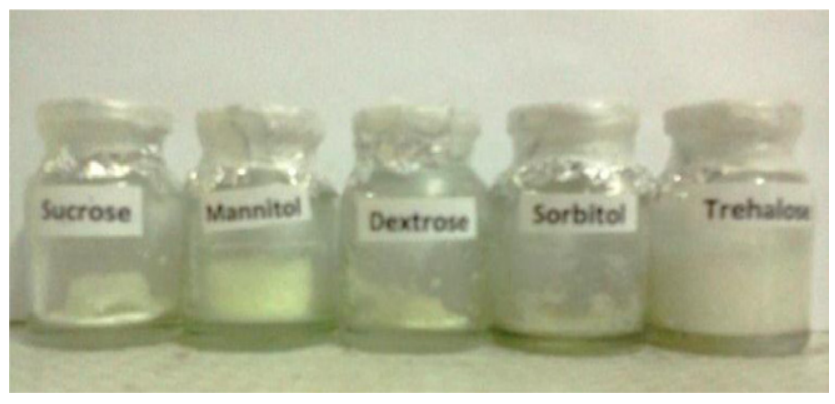

Figure 12: Physical appearance of lyophilized raloxifene hydrochloride loaded nanoparticles with different (Sucrose, Mannitol, Dextrose, Sorbitol and Trehalose) lyoprotectants.

\section{b) X- Ray Diffraction (XRD)}

XRD images of drug, polymer and nanoparticles (Figure 14) shows that the raloxifene hydrochloride was present in the crystalline state before the nanoparticles formation, but after the formation of nanoparticles the drug changed to amorphous state which confirms that after the formation of nanoparticles drug gets molecularly dispersed in the polymeric matrix.

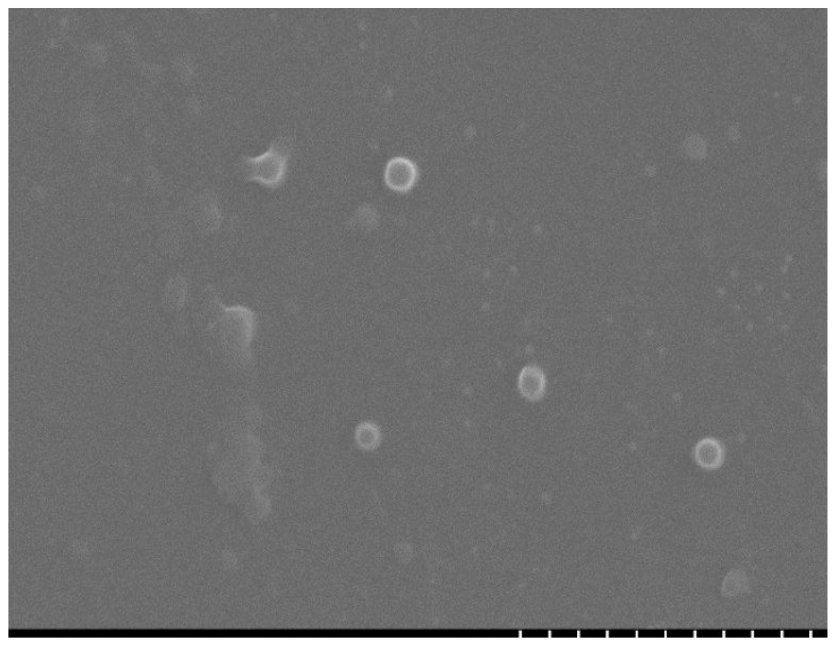

Figure 13: SEM image showing morphology of lyophilized raloxifene hydrochloride loaded nanoparticles.

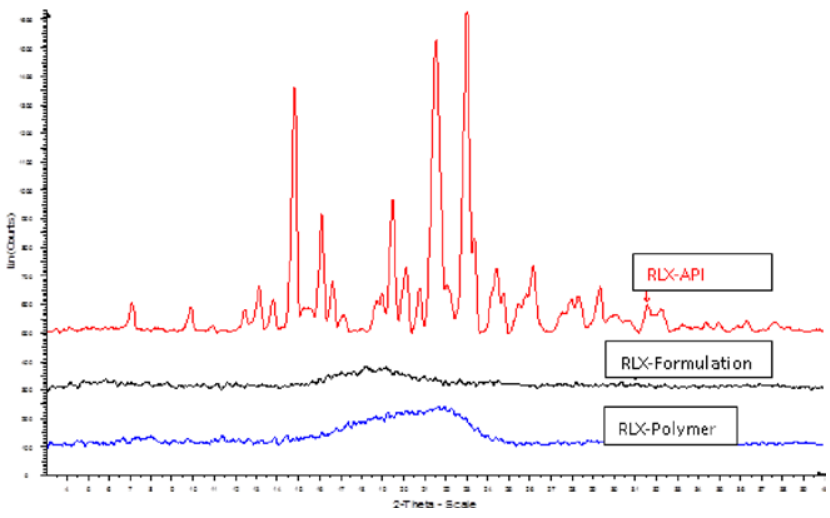

Figure 14: XRD showing nature of raloxifene hydrochloride.

\begin{tabular}{|c|c|c|c|c|c|}
\hline Lyoprotectant & $S_{i}$ & $S_{f}$ & $S_{f} / S_{i}$ & $\begin{array}{c}\text { Physical } \\
\text { appearance }\end{array}$ & Redispersibility \\
\hline Dextrose & $177 \pm 4.3$ & $228 \pm 1.7$ & 1.28 & Intact fluffy cake & ** \\
\hline Sucrose & $177 \pm 4.3$ & $232 \pm 3.0$ & 1.31 & Collapsed cake & * \\
\hline Trehalose & $177 \pm 4.3$ & $198 \pm 7$ & 1.11 & Intact fluffy cake & ** \\
\hline Mannitol & $177 \pm 4.3$ & $181 \pm 2$ & 1.02 & Intact fluffy cake & $* * *$ \\
\hline Sorbitol & $177 \pm 4.3$ & $210 \pm 3.7$ & 1.18 & Intact fluffy cake & * \\
\hline
\end{tabular}

$\mathrm{S}_{\mathrm{f}}=$ Particle size after freeze drying $\mathrm{S}_{\mathrm{i}}=$ Particle size before freeze drying

$* * *$ Reconstitution in $1 \mathrm{ml}$ water and cake is easily resuspended within 20 sec by mere shaking

** Cake is resuspended within few min by mere shaking

* Reconstitution requiring overtaxing for 2 min 


\section{In-vitro release study}

Release study was performed in Phosphate buffer saline $(0.1 \mathrm{M})$ containing $0.5 \%$ Tween $^{\circledR} 80$. The raloxifene hydrochloride exhibited a biphasic release behavior with initial first phase of fast release followed by sustained release for 20 days. The release profile of raloxifene hydrochloride loaded nanoparticles was shown in (Figure 15). About $72 \%$ of drug was released from NPs in 20 days. The main reason for prolonged release was due to the degradation of PLA block to form lactic acid which results in formation of low molecular weight polymer chains and PEG content was increased due to its non-degradable nature which ultimately results in formation of micelles and prolonging the release. The release profiles fitted in kinetic models characterized by correlation coefficient (R2) values showed zero order $(r 2=0.705)$, first order $(r 2=0.727)$, higuchi $(r 2=0.882)$ and hixon crowell $(r 2=0.547)$. The release profile of drug from nanoparticles was found to follow Higuchi diffusion controlled release model.

\section{In vitro cytotoxicity of nanoparticles}

In vitro cytotoxicity study was performed on MCF-7 breast cancer cell line to determine $\mathrm{IC}_{50}$ concentration of raloxifene hydrochloride loaded mPEG-PLA

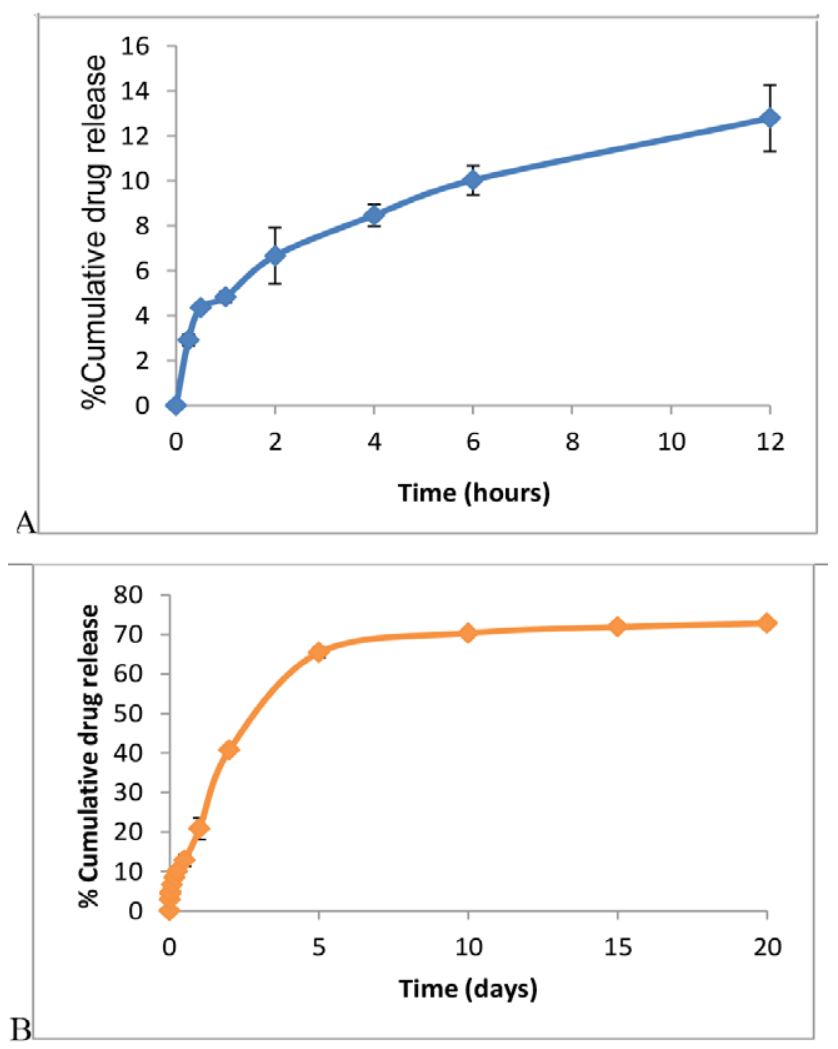

Figure 15: Raloxifene hydrochloride release profile by dialysis bag method. A: Figure showing zoom view of time points in hours B: Figure showing time points in days. nanoparticles at different formulation exposure time points. It was observed that raloxifene loaded nanoparticles had $\mathrm{IC}_{50}$ value of $55 \mu \mathrm{M}$ and $40 \mu \mathrm{M}$ at the exposure time of $48 \mathrm{~h}$ and $72 \mathrm{~h}$, respectively. However, raloxifene drug solution had $\mathrm{IC}_{50}$ value of $120 \mu \mathrm{M}$ and $70 \mu \mathrm{M}$ at the exposure time of $48 \mathrm{~h}$ and $72 \mathrm{~h}$, respectively (Figure 16). It may be concluded that $\mathrm{IC}_{50}$ value obtained in drug loaded nano-formulation is lower than free drug solution which indicate that all tested drug loaded nanoparticles significantly reduced $\mathrm{IC}_{50}$ values in MCF-7 cell lines over free drug.

\section{Stability studies of nanoparticles}

\section{Stability studies in Gastro Intestinal fluids}

The stability of the nanoparticles in SGF ( $\mathrm{pH} 1.2)$ for $2 \mathrm{hr}$ and SIF ( $\mathrm{pH}$ 6.8) for $6 \mathrm{hr}$ indicate that the interaction between the nanoparticles and the digestive fluids was reduced because of the PEG content around the nanoparticles. ${ }^{36}$ There was almost no change in the particle size and drug content in the simulated GI fluids when compared to the normal freeze dried formulation and it infers that the mPEG-PLA nanoparticles have a promising future as drug delivery systems for oral administration (Table 10).

\section{Accelerated Stability Studies}

The lyophilized nanoparticles kept in stability chamber with $5 \% \mathrm{w} / \mathrm{v}$ mannitol was stable without any collapse or shrinkage of the dried cake and has a minimum reconstitution time of about 20 sec. Particle size, physical appearance and drug content demonstrates the preservation of particle nature during the stress testing (Table 11).

\section{Pharmacokinetic study}

The plasma concentration-time profile of drug suspension $(20 \mathrm{mg} / \mathrm{kg})$ and the plasma concentration-

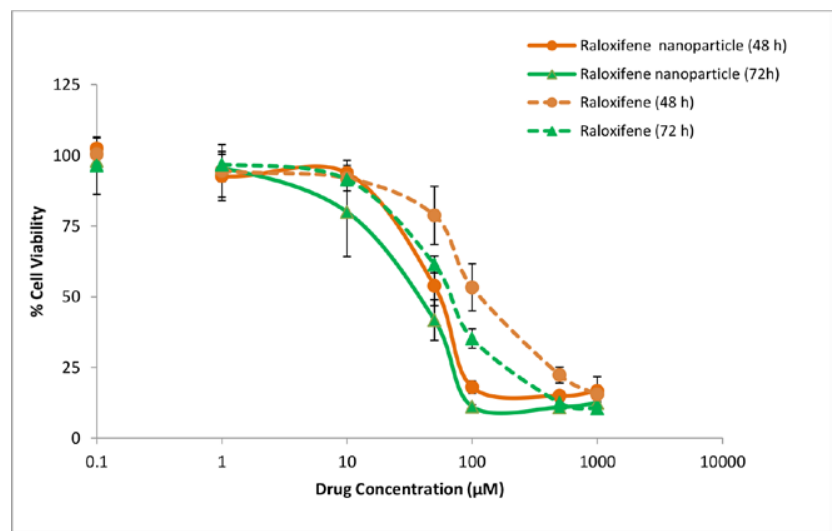

Figure 16: In vitro cytotoxic study showing \% cell viability at different concentrations and time points using MCF-7 cell lines. 


\begin{tabular}{|c|c|c|c|c|c|}
\hline \multicolumn{7}{|c|}{ Table 10: Stability of freeze dried nanoparticles in Gl fluids. } & \multirow{2}{*}{ PDI } \\
\hline & \multicolumn{2}{|c|}{ Particle size } & Drug Content (\%) \\
\hline & Initial & Final & Initial & Final & \\
\hline SGF & $181.4 \pm 3.25$ & $184.8 \pm 3.25$ & $0.12 \pm 0.03$ & $0.13 \pm 0.01$ & $94.8 \pm 2.4$ \\
\hline SIF & $181.4 \pm 3.25$ & $187.8 \pm 3.9$ & $0.12 \pm 0.03$ & $0.11 \pm 0.04$ & $96.8 \pm 2.9$ \\
\hline
\end{tabular}

(Data is expressed as mean $\pm \mathrm{SD}, n=3$ )

\begin{tabular}{|c|c|c|}
\hline \multicolumn{3}{|c|}{$\begin{array}{c}\text { Table 11: Change in Formulation Parameters after } \\
\text { Accelerated Stability Studies. }\end{array}$} \\
\hline Parameters & Initial & Final \\
\hline Particle Size & $181.4 \pm 3.25$ & $190.65 \pm 5.02$ \\
\hline PDI & $0.12 \pm 0.03$ & $0.139 \pm 0.041$ \\
\hline Drug Content (\%) & 100 (assumed) & $94.0 \pm 2.8$ \\
\hline Physical Appearance & Intact fluffy cake & Intact cake \\
\hline
\end{tabular}

(Data is expressed as mean $\pm \mathrm{SD}, n=3$ )

\begin{tabular}{|c|c|c|c|c|}
\hline Formulation studied & $\begin{array}{c}\text { Dose } \\
\text { (mg/kg) }\end{array}$ & $\underset{(n g / m l)}{C_{\max }}$ & $\begin{array}{l}t_{\max } \\
\text { (h) }\end{array}$ & 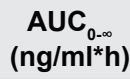 \\
\hline $\begin{array}{c}\text { Raloxifene } \\
\text { hydrochloride } \\
\text { suspension (oral) }\end{array}$ & 20 & 430 & 0.5 & 4300 \\
\hline $\begin{array}{c}\text { Raloxifene } \\
\text { hydrochloride loaded } \\
\text { nanoparticles (oral) }\end{array}$ & 20 & 900 & 1 & 20975 \\
\hline
\end{tabular}

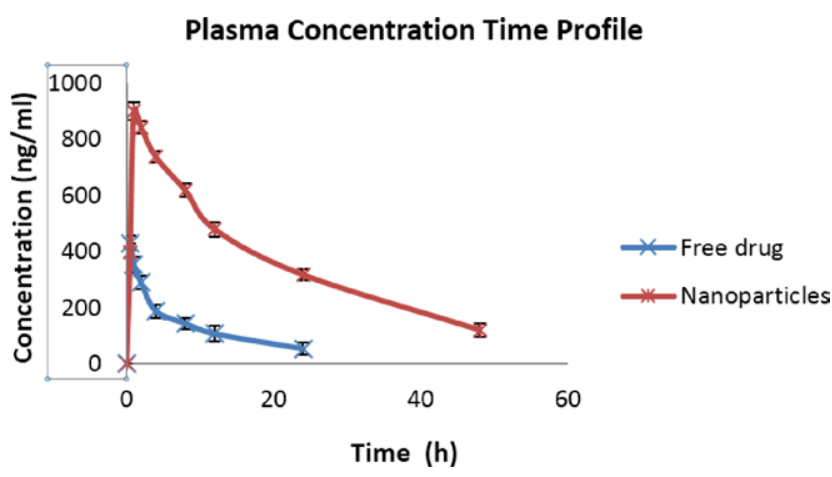

Figure 17: Comparative plasma concentration-time profile of raloxifene hydrochloride suspension (oral) and raloxifene hydrochloride loaded nanoparticles (oral) (all values are reported in mean $\pm S D, n=4)$.

time profile of drug loaded nanoparticles $(20 \mathrm{mg} /$ $\mathrm{kg}$ ) were compared as shown (Figure ) using Kinetica 5.0 software to calculate the relevant pharmacokinetic parameters such as $\mathrm{C}_{\max }, \mathrm{t}_{\text {max }}$ and $\mathrm{AUC}_{0-\infty}$ as represented (Table 12 and Figure 17). The relative bioavailability of raloxifene hydrochloride nanoparticles was approximately 4.87 times more compared to suspension which might be due to the direct uptake of nanoparticles through payer's patches and also due to prevention of metabolism of raloxifene hydrochloride since raloxifene hydrochloride is entrapped within nanoparticles.

\section{ACKNOWLEDGEMENT}

Authors are thankful to Jawaharlal Nehru Technological University for enrolling as a research scholar.

\section{CONFLICT OF INTEREST}

The authors do not report any conflict of interest pertaining to this work.

\section{ABBREVIATIONS}

ACN: Acetonitrile; AR: Analytical reagent; DCM: Dichloromethane; EA: Ethyl acetate; EE: Encapsulation efficiency; HPLC: High Pressure Liquid Chromatography; MPS: Mononuclear Phagocytic System; MWCO: Molecular Weight Cut-Off; NDDS: Novel Drug Delivery Systems; NPs: Nanoparticles; PDI: Polydispersity Index; PEG: Polyethylene Glycol; PLA: Poly-Lactic Acid; PLGA: Poly(lactide)-co-(glycolide); PVA: Polyvinyl Alcohol; RH: Relative Humidity; RLX: Raloxifene $\mathrm{HCl}$ Drug; RPM: Rotations per Minute; SD: Standard Deviation; SEM: Scanning Electron Microscopy; UV: Ultra-violet; XRD: X- Ray Diffraction.

\section{REFERENCES}

1. Jordan VC. Optimising endocrine approaches for the chemoprevention of breast cancer: Beyond the Study of Tamoxifen and Raloxifene (STAR) Trial. Eur J Cancer. 2006;42(17):2909-13.

2. Lips $\mathrm{P}$, Duong $\mathrm{T}$, Oleksik A, Black D, Cummings S, Cox D, et al. A global study of vitamin $D$ status and parathyroid function in postmenopausal women with osteoporosis: Baseline data from the multiple outcomes of raloxifene evaluation clinical trial. J Clin Endocrinol Metab. 2001;86(3):1212.

3. Patil PH, Belgamwar VS, Patil PR, Surana SJJBJoPS. Enhancement of solubility and dissolution rate of poorly water soluble raloxifene using microwave induced fusion method. Brazilian Journal of Pharmaceutical Sciences. 2013;49(3):571-8.

4. ElShagea HN, ElKasabgy NA, Fahmy RH, Basalious EBJAP. Freeze-dried self-nanoemulsifying self-nanosuspension (snesns): A new approach for the preparation of a highly drug-loaded dosage form. AAPS Pharm Sci Tech. 2019;20(7):258.

5. Davis SS, Illum L. Drug delivery systems for challenging molecules. Int J Pharm. 1998;176(1):1-8.

6. Elkasabgy NA, Abdel-Salam FS, Mahmoud AA, Basalious EB, Amer MS, Mostafa AA, et al. Long lasting in-situ forming implant loaded with raloxifene $\mathrm{HCl}$ : An injectable delivery system for treatment of bone injuries. International Journal of Pharmaceutics. 2019;571:118703. 
7. Bikiaris D, Karavelidis V, Karavas E. Novel biodegradable polyesters: Synthesis and application as drug carriers for the preparation of raloxifene HCl loaded nanoparticles. Molecules. 2009;14(7):2410-30.

8. Lee RW, Shenoy DB, Sheel R. Micellar Nanoparticles: Applications for Topical and Passive Transdermal Drug Delivery. In Handbook of Non-invasive Drug Delivery Systems William Andrew Publishing. 2010;37-58.

9. McClean S, Prosser E, Meehan E, Omalley D, Clarke N, Ramtoola Z, et al. Binding and uptake of biodegradable poly DL-lactide micro- and nanoparticles in intestinal epithelia. Eur J Pharm Sci. 1998;6(2):153-63.

10. Zambaux MF, Faivre-Fiorina B, Bonneaux FO, Marchal S, Merlin JL, Dellacherie E, et al. Involvement of neutrophilic granulocytes in the uptake of biodegradable non-stealth and stealth nanoparticles in guinea pig. Biomaterials. 2000;21(10):975-80.

11. Wei L, Anshu Y, Zhuoya L, Huibi X, Xiangliang Y. PEGylated PLGA nanoparticles as tumor necrosis factor- $\alpha$ receptor blocking peptide carriers: Preparation, characterization and release in vitro. Journal of Wuhan University of Technology--Materials Science. Edition. 2007;22(1):112-6.

12. Dong Y, Feng SS. Methoxy poly(ethylene glycol)-poly(lactide) (MPEG-PLA) nanoparticles for controlled delivery of anticancer drugs. Biomaterials. 2004;25(14):2843-9.

13. Owens III DE, Peppas NA. Opsonization, biodistribution and pharmacokinetics of polymeric nanoparticles. Int J Pharm. 2006;307(1):93-102.

14. Gabizon AA. Liposome circulation time and tumor targeting: Implications for cancer chemotherapy. Adv Drug Delivery Rev. 1995;16(2-3):285-94.

15. Harris JM, Chess RB. Effect of pegylation on pharmaceuticals. Nat Rev Drug Discovery. 2003;2(3):214-21.

16. Khalid MN, Simard P, Hoarau D, Dragomir A, Leroux JC. Long circulating poly (ethylene glycol)-decorated lipid nanocapsules deliver docetaxel to solid tumors. Pharm Res. 2006;23(4):752-8.

17. Florence AT. Nanoparticle uptake by the oral route: Fulfilling its potential? Drug Discovery Today: Technologies. 2005;2(1):75-81.

18. Peer D, Karp JM, Hong S, Farokhzad OC, Margalit R, Langer R. Nanocarriers as an emerging platform for cancer therapy. Nat Nanotechnol. 2007;2(12):75160 .

19. Pillai O, Dhanikula AB, Panchagnula R. Drug delivery: An odyssey of 100 years. Curr Opin Chem Biol. 2001;5(4):439-46.

20. Aungst BJ. Novel formulation strategies for improving oral bioavailability of drugs with poor membrane permeation or presystemic metabolism. J Pharm Sci. 1993;82(10):979-87.

21. Grama C, Ankola D, Kumar M. Poly (lactide-co-glycolide) nanoparticles for peroral delivery of bioactives. Colloids Surf, B. 2010;18:1-8.

22. Reddy PV, Rani BS, Babu GS, Rao JJJOC. RP-HPLC determination of Raloxifene in pharmaceuticl tablets. E-journal of Chemistry. 2006;3(1):60-4.
23. Kalyanaramu B, Raghubabu KJIJABC. Development of new analytical method for determination of raloxifene hydrochloride in formulations based on charge-transfer complex formation. Resrach Gate. 2011;1(2):29-33.

24. Riley T, Govender T, Stolnik S, Xiong CD, Garnett MC, Illum L, et al. Colloidal stability and drug incorporation aspects of micellar-like PLA-PEG nanoparticles. Colloids and Surfaces B: Biointerfaces. 1999;16(1-4):147-59.

25. Birnbaum DT, Kosmala JD, Henthorn DB, Peppas LB. Controlled release of beta-estradiol from PLAGA microparticles: The eff ect of organic phase solvent on encapsulation and release. J Control Release. 2000;65(3):375-87.

26. Sahana D, Mittal G, Bhardwaj V, Kumar MRJJ. PLGA nanoparticles for oral delivery of hydrophobic drugs: Influence of organic solvent on nanoparticle formation and release behavior in vitro and in vivo using estradiol as a model drug. Journal of Pharmaceutical Sciences. 2008;97(4):1530-42.

27. Auvillain M, Cavé G, Fessi H, Devissaguet JP. Lyophilisation de vecteurs colloïdaux submicroniques. STP Pharma Sci. 1989;5:738-44.

28. Abdelwahed W, Degobert G, Fessi H. Investigation of nanocapsules stabilization by amorphous excipients during freeze-drying and storage. European Journal of Pharmaceutics and Biopharmaceutics. 2006;63(2):87-94.

29. Chasteigner SD, Cavé G, Fessi H, Devissaguet JP, Puisieux F. Freeze-drying of itraconazole-loaded nanosphere suspensions: A feasibility study. Drug Dev Res. 1996;38(2):116-24.

30. Hans M, Shimoni K, Danino D, Siegel SJ, Lowman AJB. Synthesis and characterization of mPEG- PLA prodrug micelles. Biomacromolecules. 2005;6(5):2708-17.

31. Birnbaum DT, Kosmala JD, Henthorn DB, Brannon-Peppas LJJoCR. Controlled release of $\beta$-estradiol from PLAGA microparticles: The effect of organic phase solvent on encapsulation and release. Journal of Controlled Release. 2000;65(3):375-87.

32. Govender T, Stolnik S, Garnett MC, Illum L, Davis SS. PLGA nanoparticles prepared by nanoprecipitation: Drug loading and release studies of a water soluble drug. Journal of Controlled Release. 1999;57(2):171-85.

33. Hu Y, Xie J, Tong YW, Wang CH. Effect of PEG conformation on cellular yptake efficiency of nanoparticles with the HepG2 cells. Journal of Controlled Release. 2007;118(1):7-17

34. Ford AW, Dawson PJ. The effect of carbohydrate additives in the freezedrying of alkaline phosphatase. J Pharm Pharmacol. 1993;45(2):86-93.

35. Crowe JH, Crowe LM, Carpenter JF. Preserving dry biomaterials: The water replacement hypothesis. Biopharm. 1993;6:28-37.

36. Tobı $\mathrm{M}$, Sanchez A, Vila A, Soriano I, Evora C, Vila-Jato J, et al. The role of PEG on the stability in digestive fluids and in vivo fate of PEG-PLA nanoparticles following oral administration. 2000;18(3-4):315-23.

\section{SUMMARY}

Synthesized mPEG-PLA copolymer was characterized by GPC, ${ }^{1} \mathrm{HNMR}$ and FTIR and emulsion diffusion evaporation method was used to prepare nanoparticles to entrap the drug into $\mathrm{mPEG}$ PLA polymer having a particle size range $165-190 \mathrm{~nm}$ and drug loading of $8.55 \% \mathrm{w} / \mathrm{w}$ determined using validated analytical methods. Freeze dried nanoparticles showed an in-vitro release profile as bi-phasic release behavior with an initial burst effect followed by the sustained release of drug with higuchi controlled release kinetics. In vitro cytotoxicity study showed that formulation was cytotoxic with $\mathrm{IC}_{50}$ value of $55 \mu \mathrm{M}$ and $40 \mu \mathrm{M}$ at nanoparticle exposure time of $48 \mathrm{~h}$ and 72 $\mathrm{h}$ respectively. The stability studies in simulated media showed that formulation was stable in the Gl tract and can be given through oral route. Accelerated stability studies ensured the stable nature of formulation. The pharmacokinetic study showed that drug loaded nanoparticles show an increase of 4.87 times more bioavailability than the free drug. 


\section{PICTORIAL ABSTRACT}

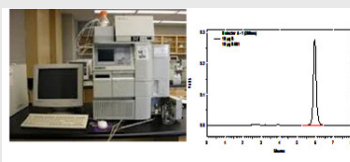

Analytical method development \& validation
Polymer synthesis \&

Characterization

GPC

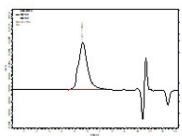

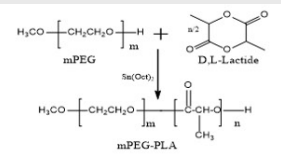

FTIR

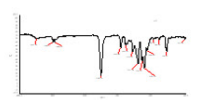

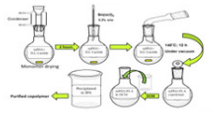

NMR

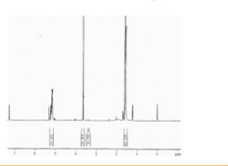

Solubility studies Nanoparticle Preparation

Freeze drying

In vitro release study
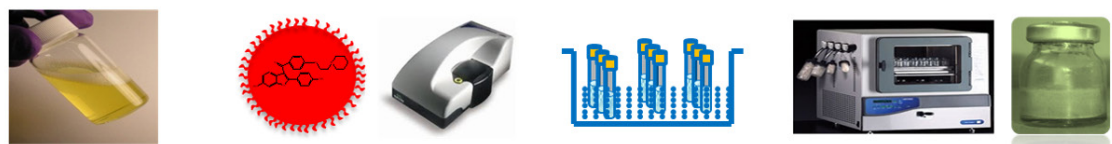

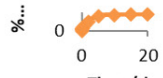

Time (days)

Characterization by SEM, XRD

Cytotoxicity study

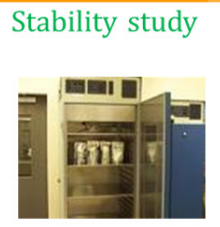

Pharmacokinetic
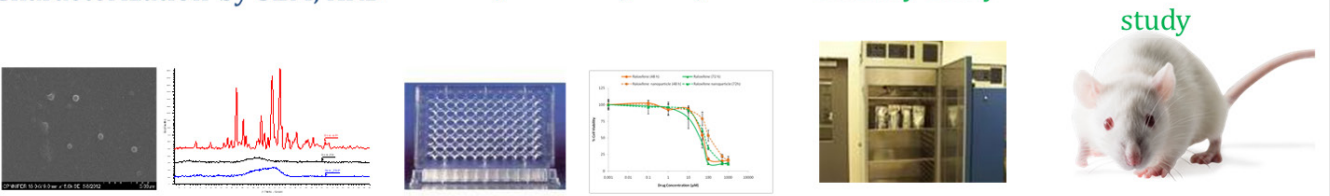

\section{About Authors}

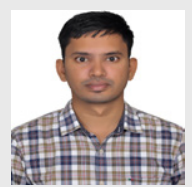

Mr. Shabari Girinath Kala Is a post graduate in Pharmaceutical Sciences working in renowned pharmaceutical organization in the field of formulation, analytical and regulatory affairs. Expertise areas include formulation development, analytical method development \& validation and quality assurance of pharmaceutical dosage forms.

Dr. Santhivardhan Chinni is an Associate Professor working in Raghavendra Institute of Pharmaceutical Education and Research (RIPER), Anantapuramu, Andhra Pradesh, INDIA.

Cite this article: Kala SG, Chinni S. Development of Raloxifene Hydrochloride Loaded mPEG-PLA Nanoparticles for Oral Delivery. Indian J of Pharmaceutical Education and Research. 2021;55(1s):s135-s148. 